\title{
Consumer Behavior Analysis in Using the Digital Payment Application
}

\author{
Radhi Aditya ${ }^{1, *}$ Fandis Ekyawan ${ }^{2}$
}

\author{
${ }^{1}$ Universitas Indonesia \\ ${ }^{2}$ Universitas Indonesia \\ *Corresponding author.Email: radhiaditya@gmail.com
}

\begin{abstract}
This study analyzes the relationship between perception and preferences on satisfaction and the usage rate of the digital payment system and the comparison of test differences between gender and age groups. To conclude the research, the relationship between usage rate and habit of using the digital payment system was also investigated. The perception dimensions included ease of use, usefulness, trust, hedonism, social, self-efficacy, attitude, and security. For the preference variable, factors studied were the types of transactions carried out on the digital payment system. For the satisfaction variable, factors studied were the level of user satisfaction in the digital payment system. For the dimensions of the usage rate, the items were the user intensity in using the digital payment applications. The data collected from the respondents were analyzed using linear regression test. From the research, it was concluded that there was a relationship between perception and satisfaction, satisfaction and preference, and perception and preference. The relationship between perception, satisfaction, as well as preference and application usage rate was partially supported, and the relationship between usage rate and habit in using the applications was also supported.
\end{abstract}

Keywords: Consumer Behavior, Digital Payment Application.

\section{INTRODUCTION}

The progression of information and digital technology has a huge impact on Indonesia. With the technological advancement, it will directly encourage and boost the innovation or adoption of technology across sectors and industries, specifically in the financial sector. The term that appears quite often lately is Fintech or Financial Technology. According to Bank of Indonesia, the terminology can be defined as the use of technology in the financial system that produces products, services, technology, and efficiency, smoothness, security, and reliability of the payment system.

There are numerous kinds of fintech products currently available in Indonesia such as electronic money or digital wallet, which is one of the most popular products or services because of its speed and practicality as their main features, especially in payment activities. Users can do the transaction anytime and anywhere using only electronic devices such as smartphones without using cash. Electronic money is also one of the fastest growing fintech products. This growth can be seen from data reported by Bank Indonesia, in which the recorded transaction volume was $2,922,698,905$ in 2018 . This figure increased $98.6 \%$ from the previous figure at the end of 2011, which recorded the transaction volume of $41,060,149$ transactions. In terms of nominal transactions, the growth has grown exponentially. Based on the data released by [1], in 2011 the nominal transaction recorded was Rp981,297 billion. Whereas in 2018 the figure reached Rp47,198,616 trillion, which means there was an increase by $97.92 \%$.

This paper tried to understand the relationship between the independent variables and usage rate and habit as the dependent variables in using the digital payment application. This research also sought the differences of the attitude or behavior between independent variables (i.g. perception, satisfaction and preference) with respect to respondent gender and age. The exponential growth of the sector, big market potential, and the fierce competition raises the questions on how these players should better understand the consumers and users in order to gain a competitive advantage over competitors in this space.

This paper is mainly based on the previous research written by [2]. Another reference was also used to further 
modify the research model by adding habit as an independent variable that was influenced by usage rate. This approach is based on the previous research written by [3], which stated that habit was influenced by prior usage.

A survey through an online questionnaire was conducted and managed to obtain 559 responses in total. Before proceeding to the main research, the answers were verified and 544 valid responses were used for further test the hypothesis. The Pearson correlation analysis and simple linear regression were used to assess the relationship between independent variables. Furthermore, regression with dummy variables were carried out to test effect of demographic factors to the research variables. Multiple regression analysis and simple regression analysis were used to test the effect of independent variables on the dependent variables. From the research, it can be concluded that there was a relationship between perception and satisfaction, satisfaction and preference, perception and preference. The relationship of perception, satisfaction, preference and application usage rate was partially supported, and the relationship of usage rate and habit in using the applications was also supported.

\subsection{Theory of Reasoned Action (TRA)}

Theory of reasoned action (TRA) uses the framework on how behavior will be determined by the behavioral intention, which will be determined by the attitude towards behavior and the social norms [4]. This theory was developed by [4] when both were analyzing the inconsistencies that occurred between attitude and behavior. TRA eventually became a reference in the development of the Technology Acceptance Model (TAM) theory, which applied a psychological approach in the process of computer adoption and information systems [5].

\subsection{Technology Acceotance Model (TAM)}

TAM was originally developed by [6], which was used to explain consumer behavior to receive and use information technology or computer. Reference [6] explained that perceived usefulness and perceived ease of use had an effect on the attitudes and behavior of individuals in the process of receiving and using technology. TAM is often referred to as the most effective approach to analyze factors that influence acceptability and behavior to use technology.

\subsection{Electronic Money}

According to the Lexicon Financial Times, electronic money can be defined as an electronic format of money that can be transferred electronically through devices such as computers or smartphones. While based on the Cambridge Dictionary definition, electronic money means money stored electronically, for example in computers or plastic cards, and can be used as payment for products or services.

There is a difference between mobile banking and mobile payment. According to [7], mobile banking is a process that connects customers with banks directly while mobile payment is a three-party process between consumers, merchants, and banks. According to the concept conveyed by [8], mobile payment is a process where one set of transactions is carried out through a mobile device (mobile phone, smartphone, etc.) that can complete financial transactions through a mobile network or technology other wireless. Another definition proposed by [9], mobile payment is the payment of goods, services, and bills with mobile devices (mobile phones, smartphones, or personal digital assistants) by utilizing wireless technology and other communication technologies.

The mobile payment consists of payments and transactions that take place between two parties quickly, comfortably, safely and simply, and can be done anytime and anywhere via mobile devices [10]. According to [11], mobile payment can benefit consumers and business entities through convenient, safe, and speedy features in the process of financial transactions.

\section{METHODS}

\subsection{Research Sample}

Survey responses were collected using web-based through Google Forms questionnaire. In total, 559 responses were collected and 544 samples from digital payment users were selected for the main research data. The framework of the digital payment in this research is the smartphone-based digital payment application that was issued by the non-banking organization. This research model was developed from [2] and [12].

\subsection{Research Model}

Numbers of statistical techniques, namely Pearson correlation and regression analysis were used to determine the relationship between independent variables considered for the study (i.g. perception, preference, and satisfaction). Moreover, regression with dummy variables was carried out to analyze the effect of different demographic factors on research variables (i.g perception, satisfaction, preference, and usage rate). To assess the relationship between independent variables and the dependent variable. To analyze the relationship between usage rate and habit as the last variable, regression analysis was used. 


\subsection{Research Hypothesis}

Based on the research and conceptual model, the hypothesis of this research is as follows:

H1: There is a positive and significant relationship between perception and satisfaction from users of digital payment application products.

$\mathrm{H} 2$ : There is a positive and significant relationship between satisfaction and preference from users of digital payment application products.

H3: There is a positive and significant relationship between perception and preference of users of digital payment application products.

H4: There are significant relationship between perception, satisfaction, preference, and usage rate, with respect from the gender dimension.

H5: There are significant relationship between perception, satisfaction, preference, and usage rate, with respect from the age dimension.

H6: There is an influence of consumer per-ception, satisfaction, and preference on the usage rate of the digital payment application.

$\mathrm{H7}$ : There is an influence of the digital payment usage rate on habit using digital payment.

\section{RESULTS AND DISCUSSION}

To test the conceptual model, regression analysis was used to assess the relationship between perception and satisfaction or the first hypothesis. Based on the research findings, it was shown that perception had a positive and significant effect on satisfaction. Hence, the first hypothesis was supported. For the second hypothesis, it was also found that satisfaction had a positive and significant effect on preference, hence, the hypothesis was supported. For the third hypothesis, it was also found that perception had a significant and positive effect on preference.

Regression with dummy variable was carried out to test the fourth and the fifth hypothesis. For the fourth hypothesis, there was no proof that there was a significant difference between perception, satisfaction, preference, and usage rate with respect to respondents gender. For the fifth hypothesis, there was a significant difference between perception, satisfaction, preference, and usage rate with respect to age, hence the hypothesis was partially supported.

For the sixth hypothesis, multiple regression analysis was used to assess the relationship between independent variables (i.g. perception, satisfaction, and preference) to the usage rate variable. It was revealed that only satisfaction had a positive and significant effect on usage rate. Hence, the sixth hypothesis was partially supported.
As for the last and the seventh hypothesis, simple linear regression was carried out to prove the relationship between usage rate and habit in using digital payment application. It was found that the usage rate had a positive and significant effect on habit of using the application. Hence, the last hypothesis was supported. The summary of the hypothesis results can be seen on the Table 1, and the research model can be seen in Figure 1.

Table 1. Hypothesis summary

\begin{tabular}{|l|l|l|}
\hline No & Research Hypothesis & Results \\
\hline 1) & $\begin{array}{l}\text { H1: There is a positive and } \\
\text { significant relationship } \\
\text { between perception and } \\
\text { satisfaction from users of } \\
\text { digital payment application } \\
\text { products. }\end{array}$ & Supported \\
\hline 2) & $\begin{array}{l}\text { H2: There is a positive and } \\
\text { significant relationship } \\
\text { between satisfaction and } \\
\text { preference from users of } \\
\text { digital payment application } \\
\text { products. }\end{array}$ & Supported \\
\hline 3$)$ & $\begin{array}{l}\text { H3: There is a positive and } \\
\text { significant relationship } \\
\text { between perception and } \\
\text { preference of users of digital } \\
\text { payment application products. }\end{array}$ & Supported \\
\hline 4$)$ & $\begin{array}{l}\text { H4: There are significant } \\
\text { relationship between } \\
\text { perception, satisfaction, } \\
\text { preference, and usage rate, } \\
\text { with respect from the gender } \\
\text { dimension. }\end{array}$ & Rejected \\
\hline 5) & $\begin{array}{l}\text { H5: There are significant } \\
\text { relationship between } \\
\text { perception, satisfaction, } \\
\text { preference, and usage rate, } \\
\text { with respect from the age } \\
\text { dimension. }\end{array}$ & $\begin{array}{l}\text { Partially } \\
\text { Supported } \\
\text { digital payment. } \\
\text { between the digital payment } \\
\text { usage rate on habit using } \\
\text { satisfaction, and preference on } \\
\text { the usage rate of the digital } \\
\text { payment application. }\end{array}$ \\
\hline 7$)$ & $\begin{array}{l}\text { H7: There is an influence } \\
\text { bence }\end{array}$ & Supported \\
\hline
\end{tabular}




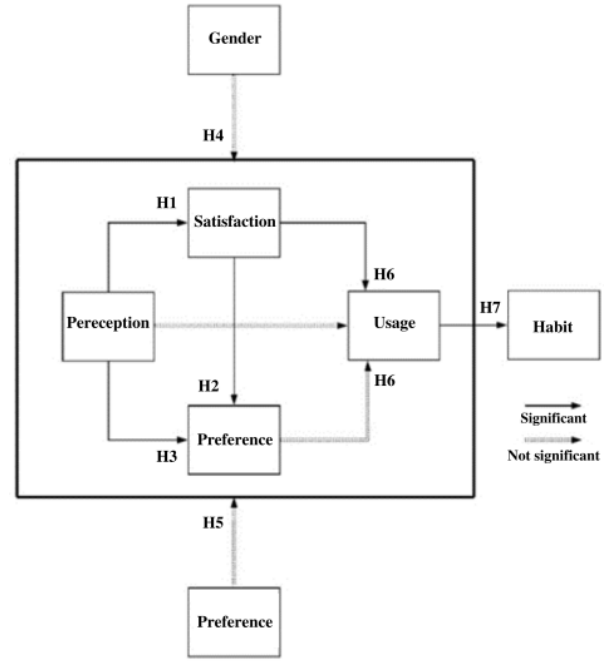

Figure 1 Research model and results.

\section{CONCLUSIONS}

Based on the analysis of the research hypotheses that have been conducted, a number of conclusions can be developed, which is shown as follows:

There was a positive and significant relationship between perception and satisfaction of users of digital payment application products. This result is in accordance with the research conducted by [2], which also became the main reference in this study. These results indicated that the perception variables and satisfaction variables had a significant influence on consumers to use digital payment applications.

There was a positive and significant relationship between satisfaction and preference from users of digital payment application products. These results are consistent with the results conducted by [2] and it can be assumed that if consumers or users feel satisfied in using digital payment services, then there is a tendency for these consumers to use the available digital payment service options.

There was a positive and significant relationship between perception and preference of users of digital payment application products. This result is in accordance with the research results conducted by [2]. In this study, it can be seen that the dimensions of the perception variable, all of which had an influence on the preference variable.

There was no significant difference between perception, satisfaction, preference, and usage rate, from the gender dimension. The results of this study are different from previous studies conducted by [2]. This can be caused by differences in the research context from the location. Reference [2] conducted previous research in the North Indian area with mobile banking products as the object of research.
There were partial differences between perception, satisfaction, preference, and usage rate, from the age dimension. Variables that had differences in terms of age dimensions significantly were satisfaction and usage rate. Whereas for the perception and preference variables, there were no significant differences in terms of age dimensions. This finding is in contrast to the previous research conducted by [2], which stated that there were significant differences in terms of age dimensions of the research variables.

There was a partial influence between the variables of perception, satisfaction and preference of consumers on the usage rate of the digital payment application. This result is different from the research conducted by [2]. Perception variables had a negative influence on the usage rate, while the preference variable did not significantly affect the usage rate. This might be due to differences in the characteristics of respondents in Indonesia as well as the context of the research using digital payment application objects, which are considered new to the people of Indonesia. In addition, the choice of transactions provided by digital payment services that are part of the preference dimension had not all been used optimally by the users. This resulted in no finding of a relationship or significant influence of the preference variable on the usage rate variable.

There was an influence between usage rate digital payment on habit in using digital payment. This finding is in accordance with the research conducted by [12]. In this study, respondents assumed that using digital payment applications had become a new activity or habit in the community.

In this study, the level of customer satisfaction or users of digital payment application services had a significant influence on the frequency of use of this service. The service providers must be able to pro-vide or satisfy consumers because this is an important factor in the frequency or usage rate of consumers to use digital payment applications at a more intensive level.

The negative influence of this variable on the usage rate provides information that digital payment application service providers must improve various dimensions that build consumer perceptions. This will have a direct influence on the frequency of use of the digital payment application. Another factor that should be taken into consideration is that digital payment services should have new innovations as the alternative to cash payments. This means that consumers or users of digital payment applications still need more intense education related to the advantages and benefits of using digital payment options, which are closely related to various dimensions related to consumer perceptions. In this study, the preference dimension is an option or payment feature that is available, preferred, and can be done through a digital payment application. 
The research results that were not significant to the frequency of use or usage rate can be seen as additional information for digital payment service providers to be able to provide information about what payment options are available. Another important thing that should be observed by service providers is information about the benefits that can be gained by users by choosing payment through digital channels compared to conventional payment options. This education is important to build positive preferences for digital payment options, which of course will in-crease the usage rate of digital payment applications from Indonesian consumers.

\section{REFERENCES}

[1] Bank Indonesia, "Jumlah Transaksi Uang Elektronik Beredar," Bank Indonesia, 2018. [Online]. Available: https://www.bi.go.id/.

[2] N. Singh, S. Srivastava, and N. Sinha, "Consumer preference and satisfaction of M-wallets: a study on North Indian consumers,” Int. J. Bank Mark., 2017.

[3] K. L. Gwebu, J. Wang, and L. Guo, "Continued usage intention of multifunctional friend networking services: A test of a dual-process model using Facebook,” Decis. Support Syst., 2014.

[4] M. Ajzen, I., \& Fishbein, "Understanding attitudes and predicting social behaviour. New Jersey: Prentice-Hall.," Englewood Cliffs, 1980.

[5] D. H. Shin, "Towards an understanding of the consumer acceptance of mobile wallet," Comput. Human Behav., 2009.
[6] F. D. Davis, R. P. Bagozzi, and P. R. Warshaw, "User acceptance of computer technology: A comparison of two theoretical models," Manage. Sci., 1989.

[7] T. Oliveira, M. Thomas, G. Baptista, and F. Campos, "Mobile payment: Understanding the determinants of customer adoption and intention to recommend the technology," Comput. Human Behav., 2016.

[8] A. Ghezzi, F. Renga, R. Balocco, and P. Pescetto, "Mobile payment applications: Offer state of the art in the Italian market," info, 2010.

[9] T. Dahlberg, N. Mallat, J. Ondrus, and A. Zmijewska, "Past, present and future of mobile payments research: A literature review," Electron. Commer. Res. Appl., 2008.

[10]F. Liébana-Cabanillas, I. Ramos de Luna, and F. J. Montoro-Ríos, "User behaviour in QR mobile payment system: the QR Payment Acceptance Model," Technol. Anal. Strateg. Manag., 2015.

[11] V. L. Johnson, A. Kiser, R. Washington, and R. Torres, "Limitations to the rapid adoption of $\mathrm{M}$ payment services: Understanding the impact of privacy risk on M-Payment services," Comput. Human Behav., 2018.

[12]T. C. K. Huang, I. L. Wu, and C. C. Chou, "Investigating use continuance of data mining tools,” Int. J. Inf. Manage., 2013. 